\title{
EPIDEMIOLOGICAL STUDY ON TENDON RUPTURES OF THE KNEE EXTENSOR MECHANISM AT A LEVEL 1 HOSPITAL
}

Rodrigo Pires e Albuquerque', Juliano Prado², Rafael Hara², Evaldo Ferreira², Leonardo Schiavo², Vincenzo Giordano ${ }^{3}$, Ney Pecegueiro do Amaral $^{4}$, João Mauricio Barretto ${ }^{5}$

\section{ABSTRACT}

Objectives: The purpose of the present study was to review the epidemiological aspects of tendon ruptures of the knee extensor apparatus at a level 1 hospital. Methods: We retrospectively analyzed 76 lesions of the knee extensor apparatus that were treated surgically at the Miguel Couto Municipal Hospital between March 2004 and March 2011. We took into consideration age, sex, trauma mechanism, anatomical classification of the lesion, affected side, comorbidities and associated lesions. Results: Among the patients studied, 68 were male and the mean

\section{INTRODUCTION}

Extensor mechanism injuries of the knee are rare. There are numerous comorbidities that predispose to the occurrence of this type of injury. Excessive sports activity and the chronic use of certain medications also facilitate tendon ruptures.

Epidemiological studies are fundamental tools for understanding the occurrence of the injury. In this study, we observe age, sex, and the most frequent type of injury, as well as the risk factors that should be observed in the prevention of extensor mechanism injuries of the knee. The aim of this work is to carry out a retrospective epidemiological study of tendon ruptures of the extensor mechanism of the knee at a level I trauma hospital.

\section{METHODS}

Seventy-six knee extensor mechanism injuries, treated surgically at a level I trauma hospital in the age was 36 years. Regarding the trauma mechanism, 62 lesions occurred due to direct trauma; the right side was affected in 21 cases; eight presented comorbidities and four presented associated lesions. Conclusion: The majority of the patients were male, at an economically active age (young people), and were victims of direct trauma. Ruptures of the patellar ligament were the most frequent lesions. Associated lesions were rare and comorbidities were infrequent in our sample.

Keywords- Epidemiology; Knee; Rupture period March 2004 to March 2011, were retrospectively analyzed. The research was carried out through an active search on the database of the Hospital Municipal Miguel Couto (HMMC), using the search term International Classification of Diseases (ICD) M66, which corresponds to spontaneous rupture of synovium or tendon. After that, based on the patient's record number at the HMMC, a search was carried out on the medical records and image archives of the respective patients. The inclusion criteria were patients of both sexes and all ages, submitted to surgical treatment for tendon ruptures of the knee extensor mechanism, regardless of whether they had associated lesions or comorbidities. Those treated by a non-surgical method were excluded, as were those whose patient record and/or imaging exams were missing some item of data considered in our work. Tendon ruptures in other regions were also excluded from our analysis. Age, sex, affected side, comorbidities, trauma mechanism

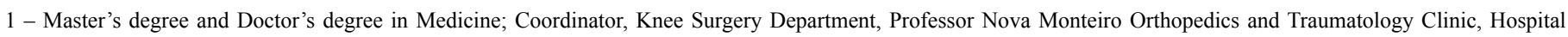
Municipal Miguel Couto (SOT-HMMC) - Rio de Janeiro, RJ, Brazil.

2 - Collaborating doctor at the SOT-HMMC - Rio de Janeiro, RJ, Brazil

3 - Master's degree in Medicine; Coordinator, Medical Residency Program of the SOT-HMMC - Rio de Janeiro, RJ, Brazil.

4 - Master's degree in Medicine; Head of the SOT-HMMC - Rio de Janeiro, RJ, Brazil.

5 - Master's degree and Doctor's degree in Medicine; Head, Orthopedics Clinic, Santa Casa da Misericórdia do Rio de Janeiro - Rio de Janeiro, RJ, Brazil.

Study conducted at the Professor Nova Monteiro Orthopedics and Traumatology Clinic of the Hospital Municipal Miguel Couto (SOT-HMMC) - Rio de Janeiro.

Correspondence: Av. Henrique Dodsworth, 83/105, Copacabana - Rio de Janeiro, RJ. Email: rodalbuquerque@ibest.com.br

Received for publication: 11/15/2011, accepted for publication: 2/7/2012.

The authors declare that there was no conflict of interest in conducting this work 
and anatomical classification of the lesion were taken into consideration. Extensor mechanism injuries of the knee are classified as: rupture of the quadriceps tendon, fracture of the patella, rupture of the patellar ligament, and fracture of the tibial tuberosity ${ }^{(1)}$. All the patient records and radiographs in anteroposterior and profile projections of the knee were assessed by a doctor with a $\mathrm{PhD}$, member of the Brazilian Society of Knee Surgery. The results were assessed by mean and frequency of occurrence.

Of the 76 patients assessed, three were excluded from the analysis because their medical records and/or imaging exams had incomplete data in relation to the topics considered in the present study. This exclusion was due to failure to obtain information relating to the trauma mechanism of the injury. During the period of the study, there were no individuals treated by non-surgical means. In all, 73 patients were effectively included in our analysis. This study is in accordance with the Helsinki Declaration of the World Medical Association.

\section{RESULTS}

Of the 73 patients, 68 were male and five were female (Figure 1), and the mean age was 36 years (minimum of 10 and maximum of 80 years). In relation to the mechanism of the injury, 62 were by direct trauma and 11 were by indirect mechanism (Figure 2); 39 patients presented rupture of the patellar ligament, versus 34 with rupture of the quadriceps tendon (Figure 3); 52 cases were on the left side, and 21 were on the right side (Figure 4); 29\% of the injuries occurred in the muscle belly, $26 \%$ in the lower patellar pole, $22 \%$ in the osteotendinous junction, $12 \%$ in the tibial tuberosity, $7 \%$ in the tendon substance, and $4 \%$ were sleeve fractures (Figure 5); eight patients presented

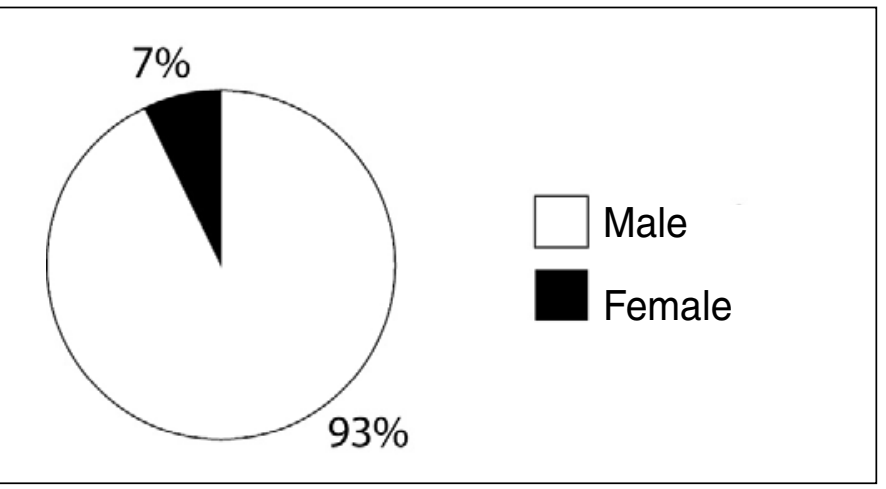

Figure 1 - Distribution by sex.

Source: Hospital Municipal Miguel Couto, 2011.

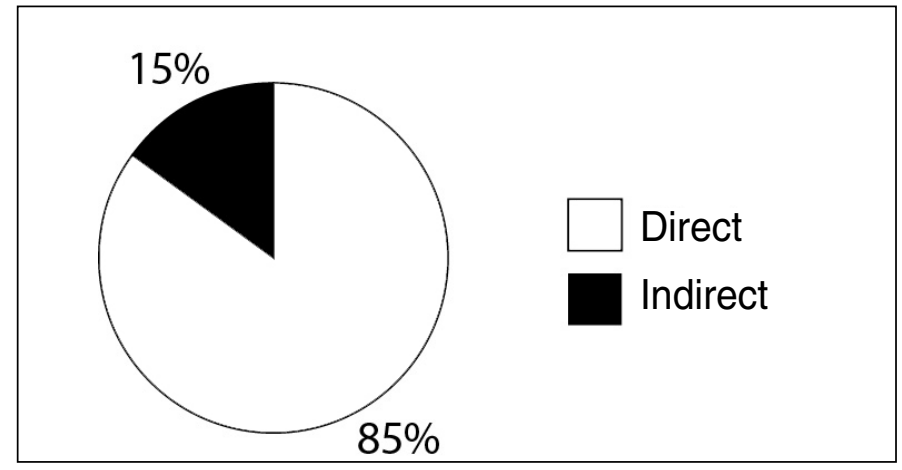

Figure 2 - Trauma mechanism.

Source: Hospital Municipal Miguel Couto, 2011.

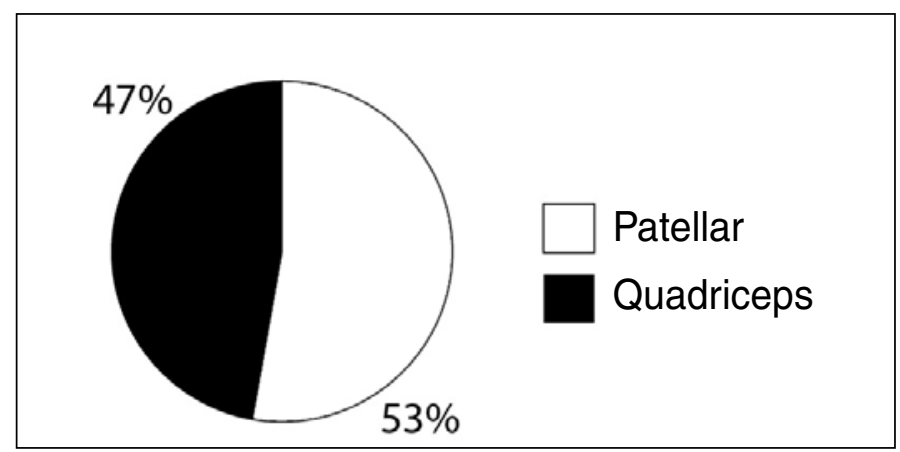

Figure 3 - Affected region.

Source: Hospital Municipal Miguel Couto, 2011.

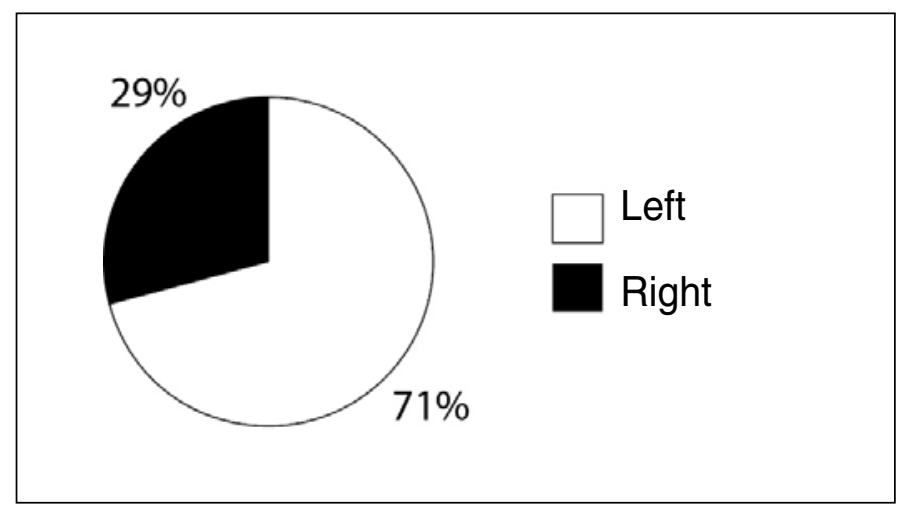

Figure 4 - Affected side.

Source: Hospital Municipal Miguel Couto, 2011.

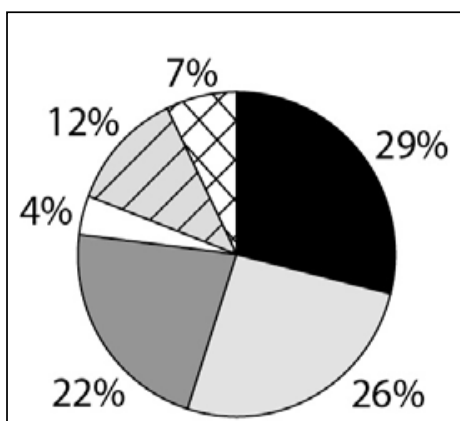

Muscle belly $29 \%$

Lower patellar pole $26 \%$

Osteotendinous junction $22 \%$

Sleeve fracture $4 \%$

Tibial tuberosity $12 \%$

Tendon substance 7\%
Figure $\mathbf{5}$ - Site of the injury.

Source: Hospital Municipal Miguel Couto, 2011. 
comorbidities, two with bilateral lesions, and four with associated lesions. Chart 1 shows the general sample of the case series.

\section{DISCUSSION}

The knee extensor mechanism injuries include patellar fractures and tendon lesions of the extensor apparatus. Patellar fractures are more frequent than tendon ruptures, with rates of $17 / 1$ and $43 / 1$, respectively $^{(2)}$. For this reason, patellar fractures were excluded, in order to better understand the epidemiology of tendon ruptures of the extensor mechanism of the knee. There is no literature to date on the epidemiology of knee extensor mechanism injuries.

Clayton and Court-Brown ${ }^{(3)}$ carried out an epidemiological study on ligament and tendon lesions of the musculoskeletal system. This research observed a percentage of 0.6 of rupture of the patellar ligament and 1.3 of rupture of the quadriceps tendon. These results confirm our findings that these are very rare injuries, even in a level I trauma clinic.

Rupture of the patellar ligament is the third most common cause of injury of the knee extensor mechanism, surpassed in number only by patellar fractures and rupture of the quadriceps tendon. It is estimated that a force of 17.5 times the body weight is needed to cause a rupture of the patellar ligament in healthy individuals $^{(4)}$. In our study, we found a higher occurrence of rupture of the patellar ligament compared with that of the quadriceps.

In our case series, males were more commonly affected, corroborating with the literature in regard to the prevalence of males over females ${ }^{(3)}$. Our view is that males, because they are physically stronger, are more susceptible to rupture of the knee extensor mechanism. Meanwhile, females have greater ligament laxity and hormonal changes due to the menstrual cycle.

Obesity is considered a predisposing factor in knee extensor mechanism injuries. Kellersmann et $\mathrm{al}^{(2)}$ believe that excess weight generates a chronic overload on the patellar ligament, making it more vulnerable to rupture. In an epidemiological study, the ideal practice would be to measure the body mass index; however, injury of the extensor apparatus of the knee incapacitates the patient from remaining in the ortostatic position, balancing the lower limb equally, which makes the discharge of weight greater on the contralateral side to the injury. For this reason, these measurements were not included in the analysis. Our view was that these measurements would be inadequately collected, generating a research bias.

The ruptures of the patellar ligament were classified according to the site of the lesion: lower patellar pole, ligament substance, and tibial tuberosity ${ }^{(5)}$. Our findings demonstrated that the lower patellar pole was the most frequent site, which corroborates with the findings in the literature ${ }^{(6)}$. In the quadriceps lesions, the most frequent site was the muscle belly. Ilan et $\mathrm{al}^{(7)}$ mention the osteotendinous junction and the muscle belly as the most common sites, corroborating with our findings.

Injuries in younger patients are generally related to physical activities, generating repetitive microtraumas. In elderly patients, meanwhile, the main causal factor is degeneration of the tendon, causing it to become weak ${ }^{(5)}$. The findings in group also agreed with this assertion. In our opinion, tendinopathies caused by excessive use, in young patients, should be better assessed and treated.

Ruptures of the patellar ligament occur in patients aged under 40 years, while ruptures of the quadriceps tendon are more common in patients over 40 years $^{(5)}$. Our research confirms these data.

Bilateral lesions of the knee extensor apparatus are largely related to the presence of comorbidities ${ }^{(7)}$. We did not observe this fact in this study.

There have been studies on structural changes in the tendon arising from microtraumas or degeneration of the tendon, leading to traumatic ruptures ${ }^{(8,9)}$. On the other hand, other researchers defend the view that direct traumatism of the knee is the cause of patellar lesions in healthy patients ${ }^{(10)}$. In this research, we observed a higher occurrence of patellar ligament rupture in young adults with no previous complaints or systemic diseases. For this reason, we defend direct trauma as the mechanism of injury, as demonstrated by Cree et $\mathrm{al}^{(11)}$. However, we agree that structural changes increase the risk of these injuries.

In the immature skeleton, the muscles, ligaments and tendons are generally stronger than the growth plates. For this reason, it is rare to find rupture of the tendon substance in children or adolescents. In the proximal region of the patellar ligament, the most common lesion is sleeve fracture, while in the distal region, we saw tibial tuberosity avulsion ${ }^{(12)}$. At our hospital, because it is a level I emergency hospital, we 
Chart 1 - General sample of the case series.

\begin{tabular}{|c|c|c|c|c|c|c|c|c|}
\hline Patient number & Age & Sex & Affected side & Injury & Injury mechanism & Location & Comorbidities & Associated injuries \\
\hline 1 & 35 & $\mathrm{M}$ & $\mathrm{R}$ & Patellar & Direct trauma & Lower patellar pole & No & No \\
\hline 2 & 40 & $\mathrm{M}$ & $\mathrm{L}$ & Quadriceps & Direct trauma & Osteotendinous junction & No & No \\
\hline 3 & 65 & $\mathrm{M}$ & $\mathrm{R}$ & Patellar & Direct trauma & Lower patellar pole & No & No \\
\hline 4 & 34 & $\mathrm{M}$ & $\mathrm{R}$ & Patellar & Direct trauma & Lower patellar pole & No & No \\
\hline 5 & 34 & $\mathrm{M}$ & $\mathrm{L}$ & Patellar & Direct trauma & Lower patellar pole & No & No \\
\hline 6 & 48 & $\bar{M}$ & $\mathrm{~L}$ & Quadriceps & Direct trauma & Muscle belly & No & No \\
\hline 7 & 45 & $\mathrm{M}$ & $\mathrm{R}$ & Quadriceps & Direct trauma & Osteotendinous junction & Renal failure & No \\
\hline 8 & 45 & $\mathrm{M}$ & $\mathrm{L}$ & Quadriceps & Direct trauma & Osteotendinous junction & Renal failure & No \\
\hline 9 & 19 & $\mathrm{M}$ & $\mathrm{R}$ & Patellar & Direct trauma & Tibial tuberosity & No & No \\
\hline 10 & 42 & $\mathrm{~F}$ & $\mathrm{~L}$ & Quadriceps & Direct trauma & Osteotendinous junction & No & No \\
\hline 11 & 56 & $\mathrm{M}$ & $\mathrm{R}$ & Quadriceps & Direct trauma & Osteotendinous junction & No & No \\
\hline 12 & 28 & $\mathrm{M}$ & $\mathrm{L}$ & Quadriceps & Direct trauma & Osteotendinous junction & No & No \\
\hline 13 & 33 & $\mathrm{M}$ & $\mathrm{L}$ & Patellar & Direct trauma & Lower patellar pole & No & No \\
\hline 14 & 48 & $\mathrm{~F}$ & $\mathrm{R}$ & Patellar & Direct trauma & Lower patellar pole & No & No \\
\hline 15 & 42 & $\mathrm{M}$ & $\mathrm{R}$ & Quadriceps & Direct trauma & Osteotendinous junction & No & No \\
\hline 16 & 52 & $\mathrm{M}$ & $\mathrm{L}$ & Patellar & Direct trauma & Tendon substance & No & No \\
\hline 17 & 57 & $\mathrm{M}$ & $\mathrm{L}$ & Quadriceps & Direct trauma & Osteotendinous junction & No & No \\
\hline 18 & 54 & $\mathrm{M}$ & $\mathrm{L}$ & Patellar & Direct trauma & Lower patellar pole & No & No \\
\hline 19 & 80 & $\mathrm{M}$ & $\mathrm{L}$ & Quadriceps & Direct trauma & Muscle belly & No & No \\
\hline 20 & 49 & $\mathrm{M}$ & $\mathrm{L}$ & Patellar & Indirect trauma & Tibial tuberosity & No & No \\
\hline 21 & 10 & $\mathrm{M}$ & $\mathrm{R}$ & Patellar & Direct trauma & Sleeve fracture & No & No \\
\hline 22 & 15 & $\mathrm{M}$ & $\mathrm{L}$ & Patellar & Direct trauma & Tibial tuberosity & No & No \\
\hline 23 & 25 & $\mathrm{M}$ & $\bar{R}$ & Quadriceps & Direct trauma & Muscle belly & No & No \\
\hline 24 & 35 & $\mathrm{M}$ & $\mathrm{L}$ & Quadriceps & Indirect trauma & Osteotendinous junction & No & No \\
\hline 25 & 34 & $\mathrm{M}$ & L & Quadriceps & Direct trauma & Muscle belly & No & No \\
\hline 26 & 74 & $\mathrm{M}$ & $\mathrm{L}$ & Quadriceps & Indirect trauma & Osteotendinous junction & Diabetic & No \\
\hline 27 & 37 & $\mathrm{M}$ & $\bar{L}$ & Quadriceps & Direct trauma & Muscle belly & No & No \\
\hline 28 & 46 & $\mathrm{M}$ & $\mathrm{L}$ & Quadriceps & Direct trauma & Osteotendinous junction & No & No \\
\hline 29 & 22 & $\mathrm{M}$ & $\mathrm{L}$ & Patellar & Direct trauma & Tendon substance & Exposed & Ulnar fracture \\
\hline 30 & 42 & $\mathrm{M}$ & $\mathrm{R}$ & Quadriceps & Direct trauma & Muscle belly & No & No \\
\hline 31 & 36 & $\mathrm{M}$ & $\mathrm{L}$ & Quadriceps & Indirect trauma & Muscle belly & No & No \\
\hline 32 & 38 & $\mathrm{M}$ & $\mathrm{R}$ & Patellar & Indirect trauma & Lower patellar pole & No & No \\
\hline 33 & 30 & $\mathrm{M}$ & $\mathrm{R}$ & Quadriceps & Indirect trauma & Osteotendinous junction & No & No \\
\hline 34 & 35 & $\mathrm{M}$ & $\mathrm{L}$ & Patellar & Direct trauma & Lower patellar pole & No & No \\
\hline 35 & 52 & $\mathrm{M}$ & $\mathrm{L}$ & Quadriceps & Indirect trauma & Osteotendinous junction & Diabetic & No \\
\hline 36 & 45 & $\mathrm{M}$ & $\mathrm{L}$ & Quadriceps & Direct trauma & Muscle belly & No & No \\
\hline 37 & 26 & $\mathrm{M}$ & $\mathrm{R}$ & Patellar & Direct trauma & Muscle belly & No & Tibial fracture \\
\hline 38 & 24 & $\mathrm{M}$ & $\mathrm{R}$ & Quadriceps & Direct trauma & Muscle belly & No & Exposed \\
\hline 39 & 34 & $\mathrm{~F}$ & $\mathrm{R}$ & Patellar & Direct trauma & Lower patellar pole & No & No \\
\hline 40 & 20 & $\mathrm{M}$ & $\mathrm{L}$ & Patellar & Direct trauma & Lower patellar pole & No & No \\
\hline 41 & 66 & $\mathrm{M}$ & $\mathrm{L}$ & Quadriceps & Indirect trauma & Osteotendinous junction & Diabetic & No \\
\hline 42 & 48 & $\mathrm{M}$ & $\mathrm{R}$ & Quadriceps & Indirect trauma & Muscle belly & No & No \\
\hline 43 & 40 & $\mathrm{M}$ & $\mathrm{L}$ & Patellar & Direct trauma & Lower patellar pole & No & No \\
\hline 44 & 49 & $\mathrm{M}$ & $\mathrm{L}$ & Patellar & Direct trauma & Lower patellar pole & Renal failure & No \\
\hline 45 & 49 & $\mathrm{M}$ & $\bar{R}$ & Quadriceps & Direct trauma & Muscle belly & Renal failure & No \\
\hline 46 & 62 & $\mathrm{M}$ & $\mathrm{L}$ & Quadriceps & Indirect trauma & Muscle belly & Diabetic & No \\
\hline 47 & 47 & $\mathrm{M}$ & $\mathrm{L}$ & Patellar & Direct trauma & Lower patellar pole & No & No \\
\hline 48 & 38 & $\mathrm{M}$ & $\mathrm{L}$ & Quadriceps & Direct trauma & Osteotendinous junction & No & No \\
\hline 49 & 29 & $\mathrm{M}$ & $\mathrm{L}$ & Patellar & Direct trauma & Muscle belly & Exposed & Femoral $+\mathrm{R}$ tibial fracture \\
\hline 50 & 23 & $\mathrm{M}$ & $\mathrm{L}$ & Quadriceps & Direct trauma & Muscle belly & No & Femoral $+\mathrm{L}$ tibial fracture \\
\hline 51 & 24 & $\mathrm{M}$ & $\mathrm{L}$ & Patellar & Direct trauma & Tendon substance & No & No \\
\hline 52 & 47 & $\mathrm{M}$ & L & Patellar & Direct trauma & Lower patellar pole & No & No \\
\hline 53 & 69 & $\mathrm{M}$ & $\mathrm{L}$ & Patellar & Direct trauma & Tibial tuberosity & Diabetic & No \\
\hline 54 & 27 & $\mathrm{M}$ & $\mathrm{L}$ & Patellar & Direct trauma & Tendon substance & No & No \\
\hline 55 & 27 & $\mathrm{M}$ & $\mathrm{R}$ & Patellar & Direct trauma & Tendon substance & No & No \\
\hline 56 & 11 & $\mathrm{M}$ & $\mathrm{L}$ & Patellar & Direct trauma & Sleeve fracture & No & No \\
\hline 57 & 11 & $\mathrm{M}$ & $\mathrm{L}$ & Patellar & Direct trauma & Lower patellar pole & No & No \\
\hline 58 & 15 & $M$ & $\mathrm{~L}$ & Patellar & Direct trauma & Tibial tuberosity & No & No \\
\hline 59 & 25 & $\bar{M}$ & $\mathrm{R}$ & Patellar & Direct trauma & Lower patellar pole & No & No \\
\hline 60 & 42 & $\mathrm{M}$ & $\mathrm{L}$ & Quadriceps & Direct trauma & Muscle belly & No & No \\
\hline 61 & 36 & $\mathrm{M}$ & $\mathrm{L}$ & Patellar & Direct trauma & Lower patellar pole & No & No \\
\hline 62 & 36 & $M$ & $\mathrm{~L}$ & Quadriceps & Direct trauma & Muscle belly & No & No \\
\hline 63 & 62 & $\bar{M}$ & $\mathrm{~L}$ & Quadriceps & Direct trauma & Muscle belly & Diabetic & No \\
\hline 64 & 23 & $\mathrm{M}$ & L & Patellar & Direct trauma & Lower patellar pole & No & No \\
\hline 65 & 12 & $\mathrm{M}$ & $\mathrm{L}$ & Patellar & Direct trauma & Sleeve fracture & No & No \\
\hline 66 & 53 & $\mathrm{M}$ & $\mathrm{L}$ & Quadriceps & Indirect trauma & Muscle belly & Lupus & No \\
\hline 67 & 13 & $\mathrm{M}$ & $\mathrm{L}$ & Patellar & Direct trauma & Tibial tuberosity & No & No \\
\hline 68 & 14 & $\mathrm{M}$ & $\mathrm{L}$ & Patellar & Direct trauma & Tibial tuberosity & No & No \\
\hline 69 & 13 & $\mathrm{~F}$ & $\mathrm{~L}$ & Patellar & Direct trauma & Tibial tuberosity & No & No \\
\hline 70 & 13 & $\mathrm{~F}$ & $\mathrm{R}$ & Patellar & Direct trauma & Tibial tuberosity & No & No \\
\hline 71 & 13 & $\mathrm{M}$ & $\mathrm{L}$ & Quadriceps & Direct trauma & Muscle belly & No & No \\
\hline 72 & 52 & $\mathrm{M}$ & $\mathrm{L}$ & Patellar & Direct trauma & Osteotendinous junction & Diabetic & No \\
\hline 73 & 43 & $\mathrm{M}$ & $\mathrm{L}$ & Quadriceps & Direct trauma & Muscle belly & No & No \\
\hline
\end{tabular}


saw extremely rare injuries in the immature skeleton (bilateral avulsion fracture of the tibial tuberosity in a 13-year-old girl, rupture of the patellar ligament and contralateral sleeve fracture in an 11-year-old boy, and rupture of the quadriceps tendon in a 13-year-old youth.

In relation to the imaging exams, the knee radiography (trauma series) provides good accuracy in the diagnostic confirmation, as well as being low in cost. We did not use ultrasound, as it is an examiner-dependent exam. On the other hand, Heyde et al ${ }^{(13)}$ recommend ultrasound in injuries of the knee extensor mechanism. In our view, magnetic resonance imaging is a high-cost imaging exam that is not available in all Brazilian hospitals. As this exam becomes more widespread, it will contribute greatly to the analysis of the condition of the tendon and the structures around the knee. We emphasize that the diagnosis of ruptures of the extensor apparatus of the knee is basically cli- nical. Imaging exams are complementary exams that assist in the surgical planning.

We believe our case series is representative, and this research is aimed at improving our understanding of the occurrence of this type of lesion, and based on these data, enabling effective prevention. Ramseier et $\mathrm{al}^{(14)}$ carried out a study on postoperative functional assessment of extensor apparatus injuries. They report on a small case study, and affirm that future research on this subject is necessary, a view with which we agree and corroborate.

\section{CONCLUSION}

The majority of the patients were male, of an economically active age (young), and victims of direct trauma, with ruptures of the patellar ligament as the most frequent injuries. Associated injuries are rare, and comorbidities were infrequent in our case series.

\section{REFERENCES}

1. Newberg A, Wales $L$. Radiographic diagnosis of quadriceps tendon rupture. Radiology. 1977;125(2):367-71.

2. Kellersmann R, Blattert TR, Weckbach $A$. Bilateral patellar tendon rupture without predisposing systemic disease or steroid use: a case report and review of the literature. Arch Orthop Trauma Surg. 2005;125(2):127-33.

3. Clayton RA, Court-Brown $\mathrm{CM}$. The epidemiology of musculoskeletal tendinous and ligamentous injuries. Injury. 2008;39(12): 1338-44.

4. Zernicke RF, Garhammer J, Jobe FW. Human patellar tendon rupture. J Bone Joint Surg Am. 1977;59(2):179-83.

5. Enad JG. Patellar tendon ruptures. South Med J. 1999;92(6):563-6.

6. Munakata T, Nishida J, Shimamura T, Ichinohe S, Abe M, Ehara S. Simultaneous avulsion of patellar apexes bilaterally in a hemodialysis patient. Skeletal Radiol. 1995;24(3):211-3.

7. Ilan DI, Tejwani N, Keschner M, Leibman M. Quadriceps tendon rupture. J Am Acad Orthop Surg. 2003;11(3):192-200.

8. Rosenberg JM, Whitaker JH. Bilateral infrapatellar tendon rupture in a patient with jumper's knee. Am J Sports Med. 1991;19(1):94-5.

9. Kannus $P$, Jozsa L. Histopathological changes preceding spontaneous rupture of a tendon. J Bone Joint Surg Am. 1991;73(10):1507-25.

10. Quintero Quesada J, Mora Villadeamigo J, Abad Rico JI. Spontaneous bilateral patellar tendon rupture in an otherwise healthy patient a case report. Acta Orthop Belg. 2003;69(1):89-92.

11. Cree C, Pillai A, Jones B, Blyth M. Bilateral patellar tendon ruptures: a missed diagnosis. Knee Surg Traumatol Arthrosc. 2007;15(11):1350-4.

12. Moretti B, Notarnicola A, Moretti L, Garofalo R, Patella V. Spontaneous bilateral patellar tendon rupture: a case report and review of the literature. Chir Organi Mov. 2008;91(1):51-5.

13. Heyde CE, Mahfeld K, Stahel PF, Kayser R. Ultrasonography as a reliable diagnostic tool in old quadriceps tendon ruptures: a prospective multicentre study. Knee Surg Traumatol Arthrosc. 2005;13(7):564-8.

14. Ramseier LE, Werner CML, Heinzelmann M. Quadriceps and patellar tendon rupture. Injury. 2006;37(6):516-9. 